\title{
Magic bullet: Paul Ehrlich, Salvarsan and the birth of venereology
}

In the years following its discovery, Salvarsan would have impacts far beyond that of syphilis treatment alone. Salvarsan's expansion would eventually reshape the broader landscape of venereal disease service delivery in the UK.

In August 1913, Paul Ehrlich presented at the International Medical Congress in London, ${ }^{1}$ where he dazzled the medical community with his new cure. ${ }^{2}$ Prompted by the novelty of Ehrlich's magic bullet, Parliament passed a resolution enacting a new Royal Commission on Venereal Diseases charged with directing venereal disease (VD) policy in the UK. The new commissioners stated that 'there are good grounds for concluding that eradication of the spirochaete with complete cure, or a total absence of subsequent signs or symptoms of the disease in the majority of cases,

\section{Box 1 Royal Commission on Venereal Diseases Instructions to Patients.}

1. Syphilis is a contagious disease; it can be cured if promptly treated by a doctor.

2. Treatment by quacks, herbalists or persons advertising so-called cures is likely to lead to disastrous results.

3. The infection may last several years. It can be conveyed to others by sexual intercourse, by kissing or using the same eating or drinking vessel, utensils or tobacco pipes, etc.

4. Treatment should not be stopped until the doctor says this may be safely done.

5. Should signs or symptoms of the disease appear, such as a rash on the skin, sore throat or symptoms of nervous disease, a doctor should be consulted at once.

6. A doctor should be consulted occasionally, even though there are no symptoms or a return of the disease.

7. Treatment need not as a rule interfere with work or necessitate a stay in a hospital.

8. No one who has, or has had, syphilis should marry without permission of the doctor; otherwise, there is great danger of giving the disease to wife and children.

9. Teeth should be cleaned in the morning. The patient should dress warmly, live simply and avoid wine, beer, spirits and other intoxicants. 
can be obtained by 'intensive treatment' when commenced in the primary stage'. ${ }^{3}$ The combination of the Wassermann diagnostic test ${ }^{4}$ and an effective treatment provided new hope for medical VD control.

Beyond focusing on syphilis' medical importance, the Royal Commission's remit centred on understanding drivers of VD prevalence and prevention of VD. Notably, the Commission did not aim to tackle the thornier moral and social issues raised by the problem, such as the commercial sex work sector (box 1). The Commission brought together key VD control interest groups, including physicians, lawyers, ministers and women's groups (yet no representatives from the armed services $^{5}$ or feminist groups). Despite this diversity, the medical community dominated the membership of the Commission: two-thirds were physicians or part of the social hygiene movement, whereas 66 of 85 witnesses called to testify were physicians. ${ }^{6}$

\section{Adriane Gelpi, ${ }^{1,2}$ Adam Gilbertson, ${ }^{1,2,3}$ Joseph D Tucker ${ }^{1,4}$}

${ }^{1}$ Institute for Global Health and Infectious Diseases, University of North Carolina at Chapel Hill, Chapel Hill, North Carolina, USA

${ }^{2}$ Social Medicine Department, University of North Carolina at Chapel Hill, Chapel Hill, North Carolina, USA

${ }^{3}$ School of Anthropology and Museum Ethnography, University of Oxford, Oxford, UK

${ }^{4}$ International Diagnostics Centre, London, UK

Correspondence to Dr Joseph D Tucker, International Diagnostics Centre, Keppel Street, London WCE1, UK; joseph.tucker@post.harvard.edu

Acknowledgements The authors would like to thank Dr Lesley Hall at the Wellcome Library and Dr Kevin Brown at the Alexander Fleming Laboratory Museum for archival assistance and Catie Gliwa for administrative assistance.

Contributors AG, AG and JDT drafted the article, contributed to the revisions and approved the final filler.

Funding Support for this work was provided by the Brocher Foundation, the UNC Center for AIDS Research (NIAID P30-AI50410), and the Social and Ethical Aspects of Research on Curing HIV Working Group (NIAID R01A108366-01). The Working Group's composition and rationale is explained at http:// searchiv.web.unc.edu/

Competing interests None.

Provenance and peer review Commissioned; internally peer reviewed.

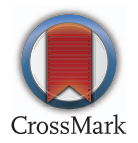

To cite Gelpi A, Gilbertson A, Tucker J D. Sex Transm Infect 2015;91:68-69.

Received 7 September 2014

Accepted 27 September 2014

Sex Transm Infect 2015:91:68-69.

doi:10.1136/sextrans-2014-051779

\section{REFERENCES}

1 Ehrlich P. Address in pathology, on chemiotherapy. BMJ 1913:2746:353-9.

2 Mazumda PM. 'In the Silence of the Laboratory': the league of nations standardizes syphilis tests. Soc Hist Med 2003:16:437-59.

3 [No authors listed]. The report of the royal commission on venereal diseases. BMJ 1916;1:380-4.

4 Wassermann A, Neisser M, Bruck C. Eine serodiagnostische Reaktion bei Syphilis. Dtsch Med Wochenschr 1906;32:745-6.

5 The royal commission on the prevalence and effects of venereal disease. Lancet 1913;182:1266.

6 Evans D. Tackling the 'Hideous Scourge': the creation of the venereal disease treatment centres in early twentieth-century Britain. Soc Hist Med 1992;5:413-33. 